Research Article

\title{
Construction of Smart City Street Landscape Big Data-Driven Intelligent System Based on Industry 4.0
}

\author{
Zhe Li $\mathbb{D}^{1},{ }^{1}$ YuKun He, ${ }^{2}$ XinYi Lu, ${ }^{1}$ HengYi Zhao, ${ }^{1}$ Zheng Zhou, ${ }^{1}$ and YinYin Cao ${ }^{1}$ \\ ${ }^{1}$ School of Architecture, Southeast University, Jiangsu 210096, China \\ ${ }^{2}$ Graduate School of Engineering, Kyoto University, Kyoto 606-8501, Japan \\ Correspondence should be addressed to Zhe Li; lizheseu@seu.edu.cn
}

Received 18 October 2021; Revised 4 November 2021; Accepted 20 November 2021; Published 14 December 2021

Academic Editor: Huihua Chen

Copyright $(0) 2021$ Zhe Li et al. This is an open access article distributed under the Creative Commons Attribution License, which permits unrestricted use, distribution, and reproduction in any medium, provided the original work is properly cited.

With the application of engineering management in smart city construction under Industry 4.0, the intelligent design of urban street landscape has attracted extensive attention. Affected by the low intelligent level of traditional landscape design, the existing urban landscape composite system has difficulty in meeting the needs of smart city construction. Therefore, this paper proposes the construction of street landscape big data-driven intelligent decision support system based on Industry 4.0. Based on the complex network theory, this paper analyzes the structure, links, nodes, driving forces, and functional requirements of urban street landscape and then puts forward the construction content and implementation method of urban street landscape intelligent decision support system. The system consists of four aspects: intelligent infrastructure, service, protection and maintenance, and management and evaluation system. Its implementation not only reflects the cooperation and effective application of intelligent technology in each stage of street landscape construction, but also provides reference for the application of engineering management in other fields under Industry 4.0.

\section{Introduction}

Based on the connectivity provided by the Industrial Internet of Things (IIoT) and the use of a variety of digital technologies such as cloud computing, big data, and artificial intelligence, Industry 4.0 is proposed as a new stage of industrial maturity $[1,2]$. These technologies have produced an industrial method of automation and interconnection involving objects, products, and people, thus achieving a higher level of industrial performance [3]. With the application of engineering management in smart city construction under Industry 4.0, the intelligent design of urban street landscape also rises and develops rapidly. Meanwhile, "intelligent" development has become the new trend in modern society due to the advancement of information technology represented by the Internet. The smart city emerges in this context, which can detect, analyze, and integrate the key information of urban core operating systems using information and communication technologies, thus making intelligent responses to various needs covering people's livelihood, environmental protection, public security, urban services, and industrial and commercial activities [4]. The intelligent urban management and operation relying on advanced information technologies can effectively solve the complex urban problems and promote the harmonious and sustainable urban development [5].

As an important part of smart city construction, landscape architecture is also facing opportunities and challenges brought by the intelligent process. Smart gardens changing the construction, operation, and management modes of traditional gardens can effectively improve the efficiency in landscape garden industry, realizing the normalization, standardization, digitization, networking, and intelligence of garden construction [6]. The typical scenario of urban street landscape has significant effects on shaping the urban image. By selecting street landscape as the entry point of smart gardens, this paper aims to explore the needs of urban street landscape and discuss the intelligent system construction and implementation means, in order to provide reference for the construction of urban street intelligent systems $[7,8]$. 
However, under Industry 4.0, in the process of intelligent city construction, how to effectively use new technologies such as big data and Internet of Things, as well as the interconnection between urban street landscapes after 5G network integration, has attracted people's attention to the security and anti-network attack stability of these systems.

\section{Related Works}

In the construction of urban street landscape intelligent system, "urban street" refers to the urban road equipped with sidewalks, municipal utilities, and various buildings on both sides in the overall length or most sections. As one of the subsystems under the future urban open complex giant system, the nature, function, form and structure of urban street are more complex than traditional urban road. Urban street serving as the most basic public urban space focuses on the citizens' life and humanized experience, which facilitates the interpersonal communication and interactions via emotional sustenance as well as playing an irreplaceable role in shaping the urban charms and vitalizing the economic development $[9,10]$.

Relying on the complex network theory and "Internet +" thinking, the smart landscape cooperates with new-generation information technologies such as Internet of Things, big data cloud computing, mobile Internet, remote sensing, and information intelligent terminal, obtains time-domain advantages, and responds quickly to social and natural activities carried in the landscape space. Integrating the spatial domain of modern ecological landscape into the large database achieves the intelligent connection between scattered social activities and needs of human beings, nature and landscape space for the interactive perception, and cognition and communication and improves the utilization and sharing rate of various scattered landscape resources, thus promoting the intelligent construction, service, and management of landscapes $[11,12]$.

The design of intelligent street landscape systems shall be based on the comprehensive consideration of user needs, greening landscapes, and basic street functions, through the Internet of Things, web services, and virtualization technology. The basic attributes, characteristic parameters, status, and other information of various street landscape elements are dynamically and intelligently sensed and accessed in real time, to build street space intensively. Through processing the information perceived by the landscape intelligent system, data collection, integration, analysis, processing, and feedback are realized under the mapping of landscape resources in urban streets. On the premise of ensuring the basic functions of the road, people's travel safety, life, and social security should be guaranteed, which provides conditions for the scientific, rapid, comprehensive, and visual development of urban street landscape design and management.

The construction of intelligent systems for urban street landscape based on complex network theory and the integration of smart landscape concept into the traditional urban street landscape indicate further improvement, which shall meet the requirements for intensive intelligent spaces, multiple interactive experience, and green ecology of energy conservation $[13,14]$.

\section{Composition of Intelligent Systems for Urban Street Landscape}

In order to cope with the multiple landscape needs under the complex system of urban streets, the intelligent street landscape system based on the complex network realizes the intelligent supply-demand matching of street landscape space services from the three levels of landscape facilities Internet of Things, service Internet, and user Internet.

The construction of street landscape intelligent system mainly involves four aspects: intelligent infrastructure, intelligent service, intelligent protection and maintenance, and intelligent management and evaluation.

3.1. Intelligent Infrastructure. Intelligent infrastructure is the physical layer and the foundation of street landscape intelligent systems. The infrastructure of street landscape intelligent systems shall proactively provide the information and services desired in addition to the basic functions and be available to correlate with other facilities and even users for the formation of a complete intelligent network featuring information interaction and function linkage, thus completing the virtualization and service-oriented information interaction and functional linkage of the intelligent information system.

3.1.1. Information Infrastructure. Information infrastructure is the basis of intelligent street landscape, covering the electric information screen shown in Figure 1, multimedia touch screen terminal shown in Figure 2, intelligent monitoring, intelligent broadcasting, help facilities, security facilities, and landscape performance facilities. The foundation of infrastructure construction lies in the sound network transmission and communication networks, and relevant facilities shall be arranged in the densely populated areas (e.g., road entrances, parking lots) to facilitate the service provision such as information inquiry and satisfy the important requirements of easy identification and convenient use. The service scope of facilities with special functions (e.g., help facilities and security facilities) shall cover the entire street area, as well as focusing on the locations along main/ secondary trunk roads and various open spaces, activity sites, and surroundings of green landscapes [15].

3.1.2. Data Infrastructure. Data cognition is the core of intelligent street landscape development. The data infrastructure is used to collect and integrate street landscape data, achieving the intelligent street landscape construction by providing the users and managers with comprehensive and intuitive information based on the integration and analysis of multisource data (basic/ business/service databases). 


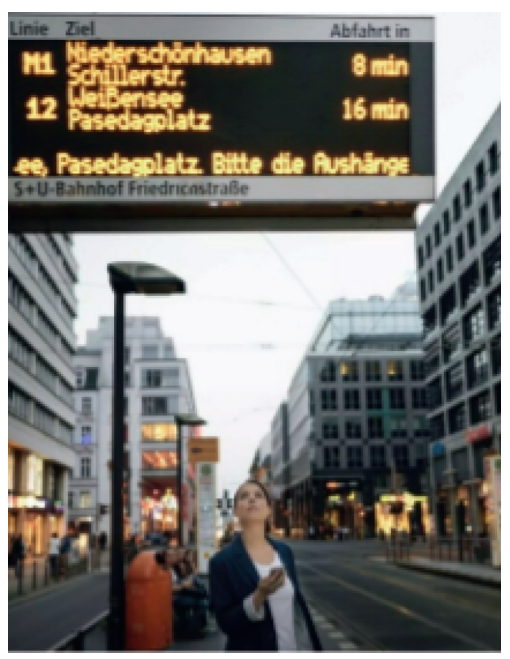

FIGURE 1: Electronic information screen.



FIgURE 2: Multimedia touch screen terminal.

Basic database clarifies the spatial location and surrounding environment of urban street landscape for the precise positioning of smart landscape. Business database has multiple subdatabases covering the special data, system planning and management, monitoring management, and industry management available for the precise and wholeprocess collection of street landscape data. Service database can provide the popular science knowledge about smart street landscape for the public and facilitate the review of various urban green spaces and scenic spots by potential travelers [16].

3.1.3. Observation Points of Street Green Space Ecosystem. Based on the ecological requirements of the street landscape intelligent system construction, ecological observation of the street is an effective measure to achieve this goal. Using RFID (radio frequency identification) technology, the realtime update of spatial ecological information of street landscape can be realized, and the location of vegetation, structures, and buildings can be monitored online. Special sensors and wireless sensor networks for street landscape ecological observation can effectively realize real-time data acquisition and transmission. Real-time monitoring of the street green space ecosystem can help with maintenance and management of the green landscape. Furthermore, the obtained ecological econometric characteristic data can aid in the formation of quantitative analysis results of the street landscape space, resulting in better landscape and ecological effects from green space maintenance and management, Figure 3.

3.2. Intelligent Service. The service object of the intelligent street landscape systems is the streetscape users. The construction of intelligent service system is based on Internet functions, which can realize the dynamic matching of the user's needs. From the perspective of users, in the process of system construction, our goals and demand motivation can be evaluated, and the service content can be derived dynamically.

In terms of qualitative or quantitative data, managers could be provided with genuine feelings, opinions, and suggestions generated by the public in the service experience. With the help of dynamic characteristics analysis of smart infrastructure, a reliable method for demand forecast management is provided. Thus, public involvement can be achieved, and the quality of the service improves continuously [17].

3.2.1. Network Service Platforms. Network service platforms are the basis for intelligent service and the guarantee for intelligent linkage with other service facilities. The construction of portals serving the public shall cover various services such as bus routes, e-maps, traffic notices, travel tips, and road service calls. In addition, the construction of mobile-based network service platforms (e.g., mobile apps, WeChat public accounts) shall also be emphasized to ensure the real-time content update and provide mobile users with street information services based on the shared portal resources.

3.2.2. Basic Street Services. Basic street services are mainly the traffic, lighting, and other necessary basic services. For instance, the smart parking management system achieves the real-time monitoring of parking spaces and the intelligent guidance about available parking spaces based on the information inquiry of parking lots and spaces through various intelligent terminals such as smart phones. The construction of public transportation system shall ensure the timely release of bus information and certain functions (e.g., multimedia information release, passenger complaint) in combination with the special bus signal system for important bus corridors and the intelligent bus stations. The streets with heavy traffic flows shall be equipped with smart toilets, which are available for the information inquiry of location and real-time usage through various intelligent terminals (e.g., smart phones, multimedia touch screens). In addition, the intelligent lighting system subject to the independent 




Figure 3: Ecosystem observation facility.

sensing, timing, voice control, or remote control of intelligent terminals shall also be arranged for the smart control of landscape lighting in different areas [18], Figure 4.

3.2.3. Road Navigation. The intelligent terminals (e.g., smart phones, multimedia touch screens) and multilanguage terminals for self-service navigation shall be arranged to facilitate the inquiry of street and surrounding-area e-maps and tour route planning as well as the scenic spot/plant introduction using QR code/RFID technologies [19].

3.2.4. Information Release. An interactive information system shall be established to provide life, service, business, and medical information for citizens, with various network service platforms serving as the channels for street information release, covering the street information, real-time road conditions, toilet usage, spare parking spaces, restaurant usage, and other basic information; climatic information (e.g., street temperature, humidity) and health information such as negative oxygen ion content in key areas Figures 5, flowering phase, and news and cultural event notices (e.g., lectures, exhibitions, festival activities, fitness events) at sites along the street; and information of emergency responses.

3.2.5. Personalized Services. Personalized services available at various network service platforms can meet the street use demands of different people [20], for instance, the online adoption of plants along the street, and regular pushing of plant growth status and daily conservation information; pushing of intelligent infrastructure, location awareness, environmental monitoring index analysis, online security, and health information via the Internet; and application of intelligent technologies based on the users' different needs of travel and fitness.

3.2.6. Consulting/Complaint Services. Compared with the traditional consulting/complaint services, the services provided through the intelligent system are more convenient and efficient, and multiple channels (e.g., street intelligent terminals, consulting/complaint pages, mobile terminals) are available for the public. The intelligent system of linkage service can achieve the unified receipt and instant feedback/ response to consultations and complaints from telephones and network terminals.

3.2.7. Virtual Experience. In order to improve the user experience, a multimedia experience center focusing on historical districts shall be constructed using multiple technologies (e.g., GIS, VR, and multimedia) for the display of historic landscapes, original natural features, and historical changes. The 3D panorama/reality enhancement display technology and $360^{\circ} / 720^{\circ}$ real-life photos or videos can be utilized to create the virtual blocks for digital virtual tours that are available at portals and terminal devices (e.g., multimedia touch screens, smart phones) $[16,21]$.

3.3. Intelligent Protection and Maintenance. Intelligent protection and maintenance are the function expansion of the user Internet based on the Internet of Things of landscape facilities. Dynamically generate landscape maintenance needs based on smart infrastructure, and dynamically match landscape maintenance needs with landscape maintenance services through the Internet of Things technology. Realize the informatization and intelligence of the protection and maintenance process, provide visual guidance on daily maintenance process and key technology, and the responsible personnel and stages could be specified for the real-time recording of maintenance process and information [22].

3.3.1. Green Space Protection and Maintenance. Green space protection and maintenance are the key to intelligent protection and maintenance, covering the digital recording, monitoring, and control of boundaries and green resources including the main plants and facilities. The important spots and key facilities shall be equipped with $3 \mathrm{D}$ scenes for inspection and comparison via intelligent terminals, mainly involving the plant irrigation and fertilization, pest and disease and freezing damage management, and intelligent cultivation.

Environmental monitoring and intelligent irrigation system can provide effective services for intelligent plant irrigation and fertilization management. The digital data processing of soil nutrients can maximize the effects of water-saving and precise irrigation, scientific management, and low-carbon maintenance [23, 24]. The construction of soil monitoring subsystem is available for the real-time monitoring of ambient temperature and humidity, wind direction, rainfall, and illuminance in the 




Figure 4: Basic street services.
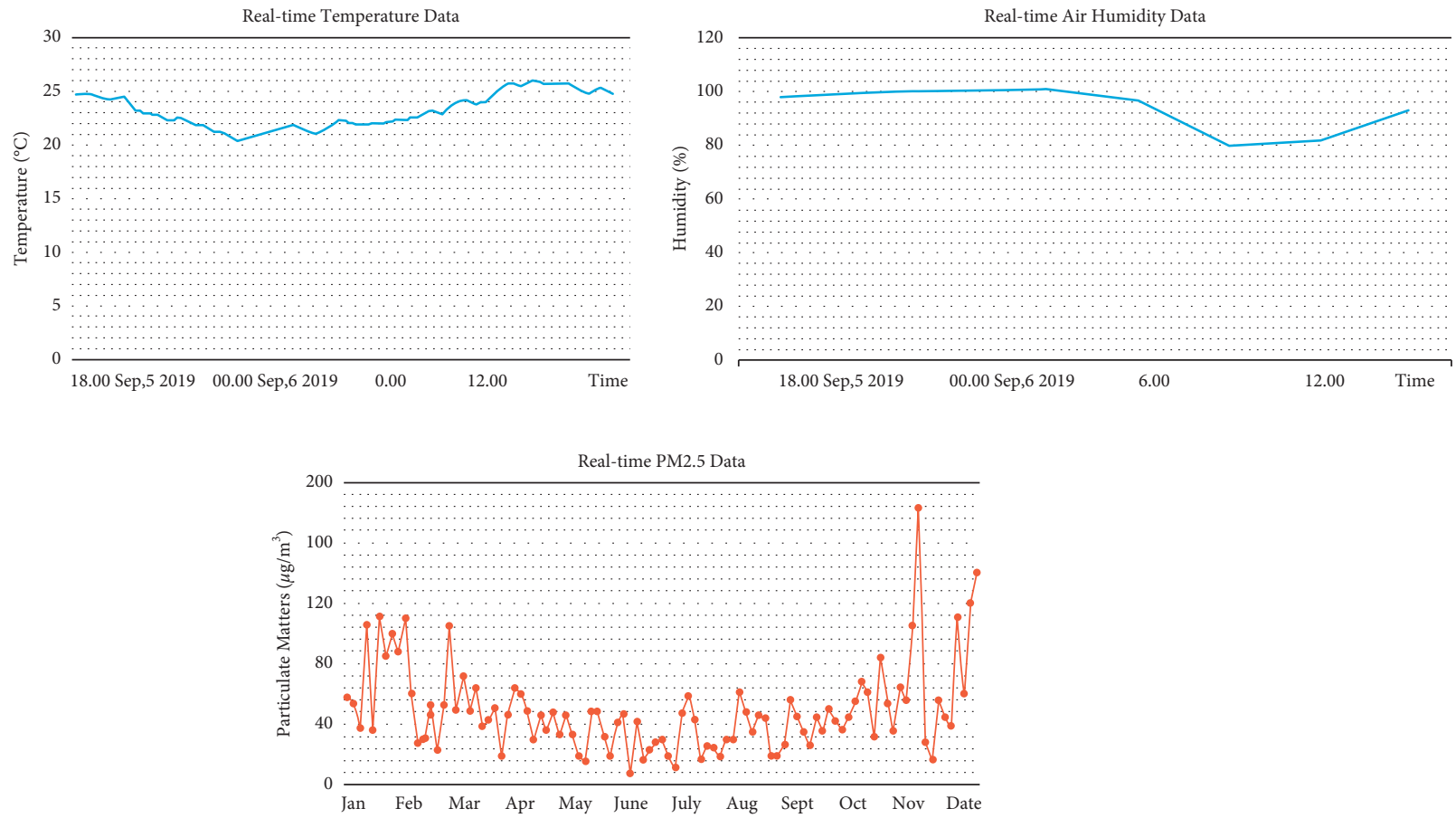

FIGURE 5: Street climatic information and health information.

surrounding environment Figure 6, with the sensing facilities adopted for real-time detection of soil moisture, fertility, and other green space indexes. Maintenance decision-making depends on the IoT-based intelligent analysis and sorting of monitoring data received by servers [25]. In addition, the sprinkling and dropper systems are used for the automatic irrigation and fertilization and other intelligent applications, and the landscaping personnel can also search and receive monitoring data and warning information via computers and mobile phones Figure 7.
The GPS positioning and FRID technologies shall be adopted for the control of plant diseases and pests, with the dynamic tracking system established to ensure the dynamic protection and monitoring of green plants as well as help technicians locate the areas of pests and diseases at first time. The implementation of "prevention-first" principle by each institution responsible for plant management and protection targeting the necessary early warning of pests and diseases within all periods can greatly reduce the prevention costs and probability of large-scale pests and diseases [26]. Early warnings for the freezing damage management shall be 

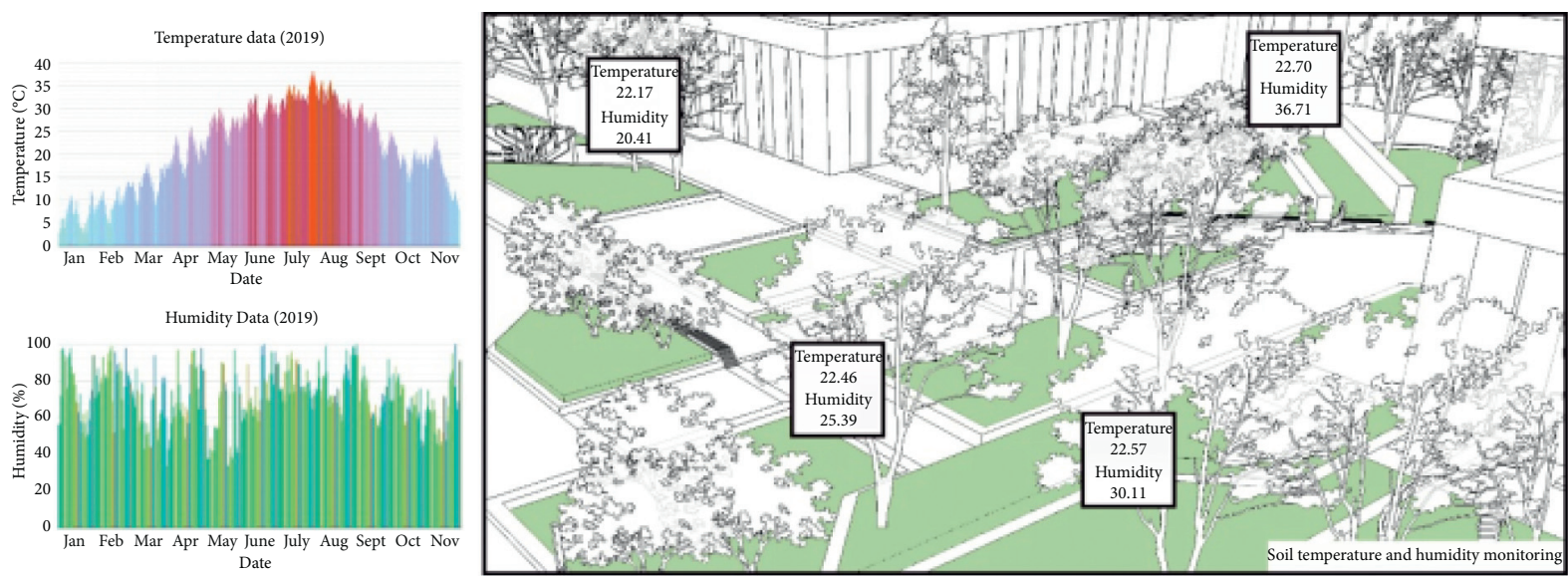

Figure 6: Soil monitoring subsystem.

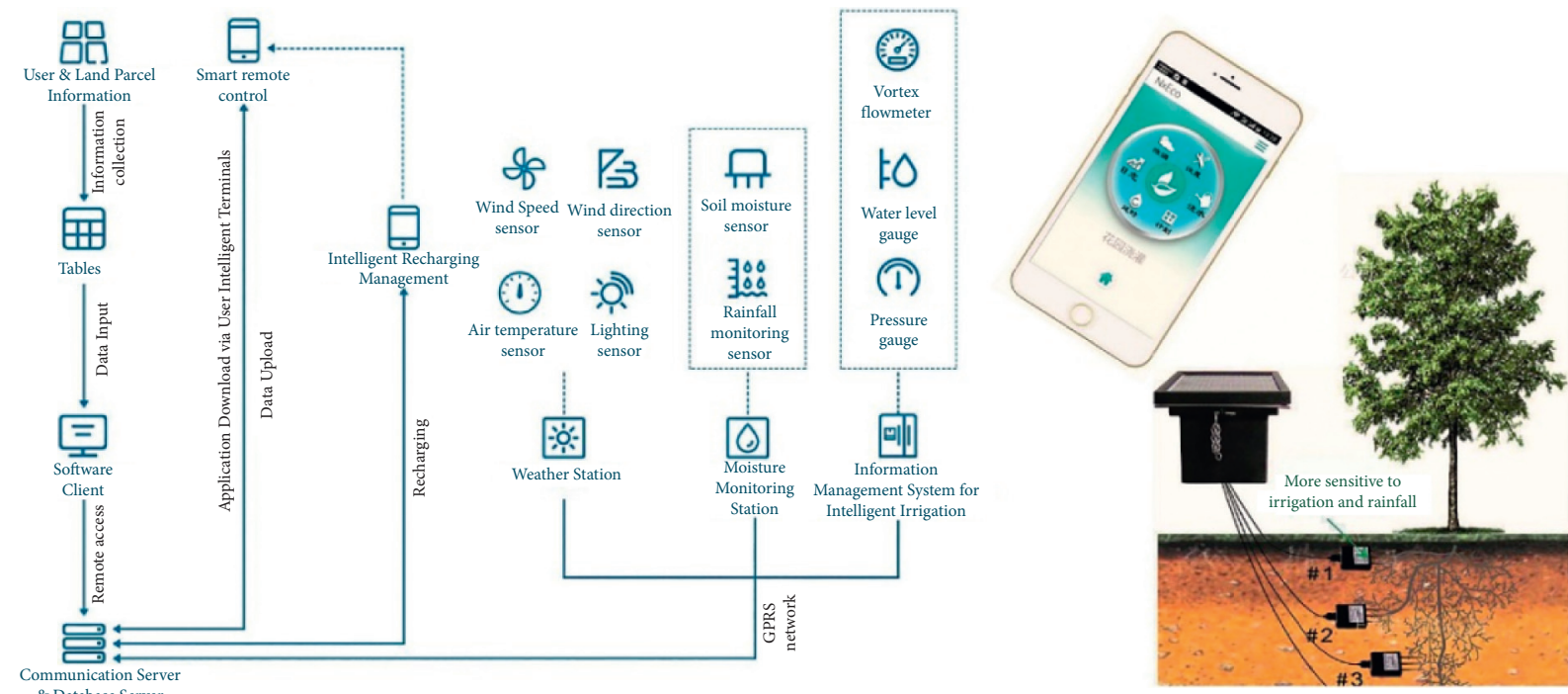

FIGURE 7: Intelligent irrigation system.

issued in advance based on the weather conditions, providing the scientific basis and guidance for plant winter protection.

The intelligent technology-based seedling planting and cultivation shall make full use of the IoT and spatial information integration technologies. The partitional measuring of regional soil quality, hydrological conditions, and microclimate factors at the stage of planting planning provides the definite data basis for breeding and rapid formulation of cultivation schemes. At the same time, a tree full cycle database shall be established for plant tracking and data sorting in the whole process, as well as the records of seedling archives, tree transplantation, and maintenance information. Intelligent cultivation can effectively prevent the challenges faced by the traditional seedling cultivation (e.g., improper layout of trees, unsatisfactory production or waste of seedlings).

3.3.2. Heritage Protection and Maintenance. Both natural heritage and cultural heritage involve heritage protection and maintenance, including ancient and famous trees and cultural relics. For the ancient and famous trees, the highdefinition photos shall be obtained based on the precise coordinate positioning via monitoring and RFID technology in addition to the normal maintenance measures, and mastering relevant detailed information will facilitate the data calling, plant protection, document management, maintenance, and rejuvenation monitoring. Digital modeling based on the growth environment of ancient and famous trees also facilitates the accurate analysis of protection measures Figure 8. For the cultural relics and historical sites surrounding the street, the $3 \mathrm{D}$ data model shall be constructed to enhance the protection. The ancient buildings shall be equipped with stress-strain sensors for deformation monitoring and risk assessment [27].

3.4. Intelligent Management and Evaluation System. Scientific and comprehensive management measures are an important prerequisite for realizing the sustainable development of streetscapes. Quantitative evaluation mechanism is an effective objective to judge the effectiveness of streetscapes. 



Figure 8: Digital monitoring of ancient and famous trees.

How to effectively integrate various scattered landscape management resources and coordinate various quantitative evaluation parameters to achieve the best match between street landscape management and demand is the key problem. Hence, quantitative data-driven evaluation and control system is ultimately conducive to the continuous optimization of landscape effects.

3.4.1. Intelligent Management. The comprehensive and scientific management shall take account of internal office work, gardening business, street security, and other related factors.

Office automation (OA) system can improve the overall efficiency of internal office work, covering process management, e-mail, document management, document circulation, approval management, working calendar, notice announcement, personal information maintenance, conference management, and attendance management.

In terms of the gardening business management, video monitoring, RFID, and infrared sensing technologies shall be adopted for the real-time perception of changes in street green resources, infrastructure, and traffic flows, as well as the automatic collection, adjustment, and update of street landscape data. The real-time monitoring of street landscape can achieve precise management and prevention against vandalism and damage caused by natural disasters.

Street security cannot be neglected considering the special traffic function of urban street with public spaces. The construction of integrated street control platform makes the daily operation monitoring and emergency command and dispatching possible, providing basic support for navigation and guidance based on the location services of GIS and satellite positioning systems [28]. Nowadays, the rapid development of information technology also facilitates the dynamic monitoring of public opinions released via key media, forums, blogs, and Weibo platform; extraction of relevant information; and timely warning/treatment of potential crisis events in accordance with predetermined strategies.

3.4.2. Intelligent Evaluation System. The evaluation of selfdiagnosis by intelligent evaluation system aims to provide reference for further development. Moreover, reasonable performance evaluation can not only measure the achievements of street landscape construction and find out the existing problems, but also provide important guidance for the continuous improvement of street landscape intelligent system.

Establishment of the complete, scientific, and effective evaluation system shall be based on the existing urban gardening standards, with the relevant street smart landscape indicators integrated into the system by means of spatial layers, forms/tables, document uploading, and image attachments for real-time computing and result judgment/analysis [29], Table 1.

\section{Technical Means of Intelligent Systems for Urban Street Landscape}

Intelligent technology refers to a specific technology or method used in the construction of an intelligent urban streetscape system. Internet of Things, spatial information integration, virtual reality and visualization technology, digital technology, etc. can solve the following problems in the construction of streetscape system under the condition of urban complex giant system:

(1) How to manage, digitize, and integrate information from scattered roads efficiently and precisely, in order to realize the effective distribution and dynamic overall grasp of the streetscape service capabilities.

(2) How to coordinate the relationship between the geographic space, data flow, time distribution, hardware network, and user needs of the streetscape intelligent system, in order to realize the spatial mapping between complex streetscape resources and intelligent system service capabilities [30].

Emergence of the most representative IoT technology in the intelligent process has led the transformation of information age into an intelligent era. The all-inclusive IoT technology involving radio frequency identification (RFID), infrared sensor, and sensor-laser scanner solves numerous urban problems via interconnection of things after the Internet-based information connection [31].

Spatial information reflects the spatial distribution characteristics of geographic entities, and the spatial information integration technology involving remote sensing (RS), geographic information system (GIS), and global positioning system (GPS) can reflect the topographical features of all sites more concretely and objectively at the 
TABLE 1: Intelligent evaluation index.

\begin{tabular}{|c|c|c|c|c|}
\hline \multirow{2}{*}{ Target layer } & \multicolumn{4}{|c|}{ Control layer } \\
\hline & Evaluation object & Weights & Indicator layer & Weights \\
\hline \multirow{12}{*}{ Evaluation of intelligent urban street landscape (A) } & \multirow{5}{*}{ Material element (B1) } & \multirow{4}{*}{0.38} & Functional facilities $(\mathrm{C} 1)$ & 0.35 \\
\hline & & & Recreation facilities (C2) & 0.3 \\
\hline & & & Plant landscape (C3) & 0.15 \\
\hline & & & Paved landscape (C4) & 0.2 \\
\hline & & \multirow{5}{*}{0.28} & Spatial scale fitness (C5) & 0.3 \\
\hline & \multirow{5}{*}{ Open space (B2) } & & Environment comfort (C6) & 0.25 \\
\hline & & & Landscape interface suitability (C7) & 0.23 \\
\hline & & & Activity type richness (C8) & 0.12 \\
\hline & & & Activity time richness (C9) & 0.1 \\
\hline & & \multirow{3}{*}{0.34} & Landscape sensitivity (C10) & 0.35 \\
\hline & \multirow[t]{2}{*}{ Environmental ecology (B3) } & & Landscape suitability (C11) & 0.33 \\
\hline & & & Landscape health (C12) & 0.32 \\
\hline
\end{tabular}

macro level and achieve precise quantification and data digitization for in-depth research and analysis [32].

VR technology integrates multiple techniques features in good experience of immersion, interaction, and conception, covering the real-time $3 \mathrm{D}$ computer graphics, 3D wide-angle (wide-field) display, tracking of the viewer's head/eyes/ hands, tactile/force feedback, stereo effects, network transmission, and voice input/output [33].

The basic process of digitization involves the transformation of all complex and changeable information into measurable data, digital data modeling for binary code conversion, and input into the computer for unified processing [34]. At present, the digital technology is widely used in various industries, and the digitization serving as the predecessor of intelligent technologies shall be utilized continuously in the intelligent era.

\section{Prospects of the Construction and Application of Intelligent Systems for Urban Street Landscape}

To achieve the successful construction of street landscape intelligent systems, the mutual mapping of complex system and complex network of street landscape needs to be realized. Therefore, the above intelligent means must be implemented combined with the actual stages of street landscape construction in practice.

5.1. Planning and Design Stage. The early stage of planning and design provides direct guidance for the mid-term construction and post-management of landscape construction. The application of intelligent means such as the Internet of Things, virtual reality, and visualization technology at the planning and design stage can realize more scientific and rational street landscape design.

In terms of on-site investigation, the traditional investigation methods have large workload and large error, and most of them are completed on the basis of on-site inspection and surveying and mapping, combined with the existing data. In addition, the traditional street design focusing on-site plane lacks the 3D-space and humanized thinking in terms of vertical design, construction scale, and detailed design. On the contrary, the intelligent landscape construction can realize the targeted integration of IoT and spatial information technologies into the site survey, with the precise positioning of street location and surrounding land uses utilizing the IoT sensing nodes [35]; moreover, the spatial information technology enables the designer to understand the connections between overall street appearance/style and urban image more comprehensively and accurately Figure 9.

5.2. Construction Stage. The construction quality directly affects the smooth implementation of the preliminary design and the cost of later maintenance and management. Due to the problems of inaccurate calculation of quantities, unconstrained construction, and limited professional quality of most construction personnel in traditional garden construction, there are often some deficiencies in construction quality compared with the expected effect.

The intelligent street landscape construction can ensure the rational resource allocation and construction efficiency through the in-depth survey of on-site environmental factors (e.g., soil quality, hydrological conditions, wind force, atmospheric pressure) using the sensing and RFID systems of IoT technology and the corresponding construction schemes and regulations. The application of spatial information integration technology and sensing system makes precise and rapid data positioning based on construction drawings possible at the stage of fixed point setting-out. The multispace model using VR technology enables the construction personnel to understand the design intention in an intuitive manner during construction, thus ensuring the realization of design effects. The application of IoT sensing system upon project acceptance for data measurement and quantitative analysis of engineering effects, combined with the direct data transmission to the auditor's mobile devices using mobile Internet technology, guarantee the strict project acceptance [36], Figure 10.

5.3. Green Plant Cultivation and Conservation Stage. Conservation management can maintain and guarantee the landscape effects after gardening construction. The 


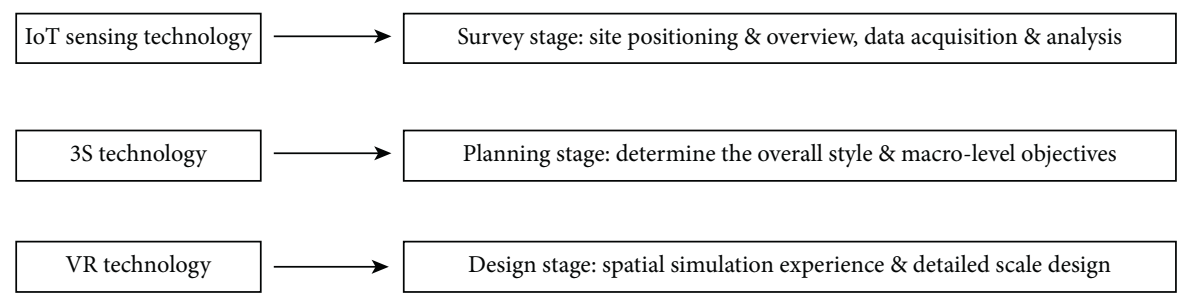

Figure 9: Application of intelligent technologies at the planning and design stage.

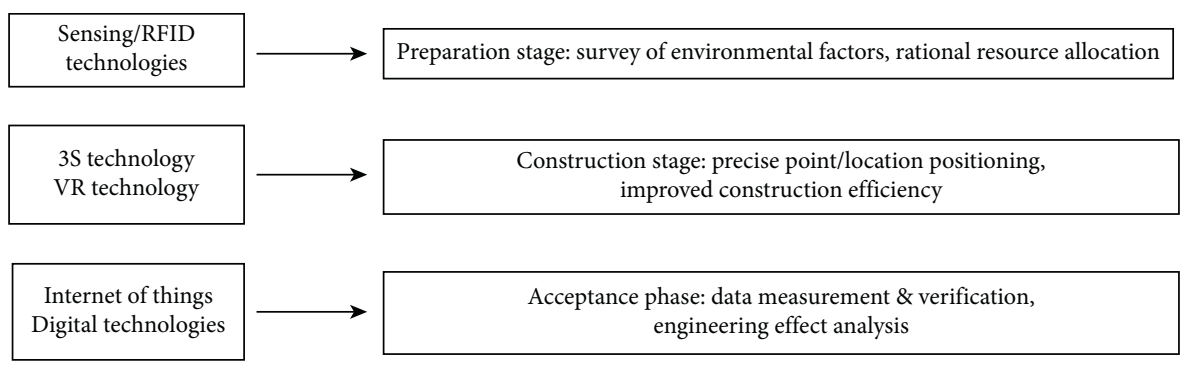

FIgURE 10: Application of intelligent technologies at the construction stage.

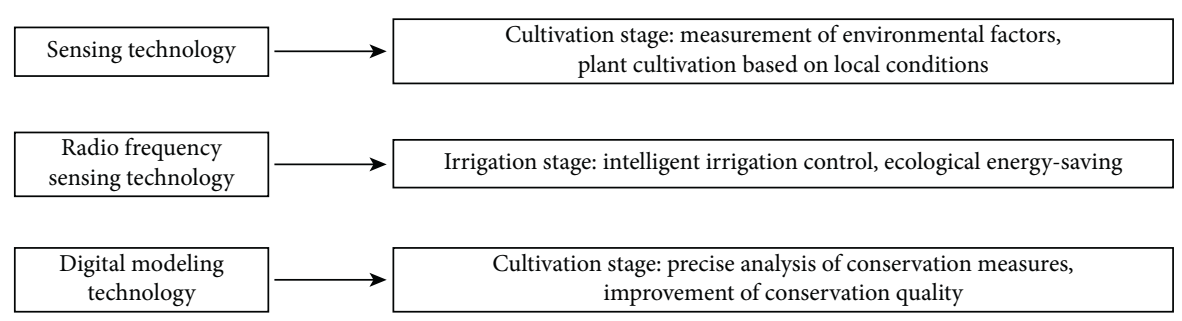

FIGURE 11: Application of intelligent technologies at the green plant cultivation and conservation stage.

traditional plant cultivation and conservation have certain shortcomings, e.g., unsatisfactory professional quality of management personnel and conservation measures of low technical contents.

The intelligent plant cultivation and conservation integrating IoT technology ensure the effective improvement of conservation efficiency and effects with reduced cost. In order to make proper use of local conditions, the sensors shall be used to measure environmental factors (e.g., humidity and soil quality) at the cultivation stage, and the original manual sprinkling shall be replaced by the sprinkling/drip irrigation system with time-frequency sensors to detect the soil moisture and facilitate the intelligent control [37]. In terms of fertilization, winter protection, and wind protection, the digital model established based on the plant growth environment can realize the precise analysis of proper measures in different periods to ensure the normal plant growth and optimal effects Figure 11.

\section{Conclusion}

Applying intelligent means in urban street landscape design and integrating street landscape intelligent system into smart city construction can actively promote urban development. Procedures starting from scheme design and project construction to maintenance management, technology introduction, and formulation of comprehensive and effective strategies are the key to the successful construction of street landscape intelligent system based on complex network. In addition, the construction of street landscape intelligent system also provides a platform for public participation and governance. The public can easily and quickly obtain information through such intelligent systems and use improved consultation/complaint services to give timely feedback to managers, which indicates that public participation has been significantly improved [7, 38, 39]. In short, the street landscape intelligent system based on complex network theory provides an advanced and sustainable construction mode for the future urban complex street system. In the context of Industry 4.0, with the rapid development of big data and the Internet of Things, more in-depth research in the future should aim to integrate the street landscape intelligent system into the construction of smart city and build a perfect street landscape intelligent system.

\section{Data Availability}

The labeled datasets used to support the findings of this study are available from the corresponding author upon request. 


\section{Conflicts of Interest}

The authors declare that there are no conflicts of interest.

\section{Acknowledgments}

This research was supported by the National Key R\&D Program of China (No. 2019YFD1100405) and its branch project (No. 2019YFD11004055). The authors thank Cheng YuNing, Xu Ning, Yuan YangYang, Han Xiao, Lin XiaoShan, and Song Shuang for their indispensable help with this research. The authors are also thankful for the data support from the Digital Landscape Laboratory of Southeast University.

\section{References}

[1] L. S. Dalenogare, G. B. Benitez, N. F. Ayala, and A. G. Frank, "The expected contribution of industry 4.0 technologies for industrial performance," International Journal of Production Economics, vol. 204, pp. 383-394, 2018.

[2] A. G. Frank, L. S. Dalenogare, and N. F. Ayala, "Industry 4.0 technologies: implementation patterns in manufacturing companies," International Journal of Production Economics, vol. 210, pp. 15-26, 2019.

[3] J. M. Müller, D. Kiel, and K.-I. Voigt, "What drives the implementation of industry 4.0 ? The role of opportunities and challenges in the context of sustainability," Sustainability, vol. 10, no. 1, p. 247, 2018.

[4] A. Kamilaris, A. Pitsillides, F. X. Prenafeta-Bold, and M. I. Ali, "A Web of Things based eco-system for urban computing towards smarter cities," in Proceedings of the 24th International Conference on Telecommunications (ICT 2017), Limassol, Cyprus, May 2017.

[5] V. Albino, U. Berardi, and R. M. Dangelico, "Smart cities: definitions, dimensions, performance, and initiatives," Journal of Urban Technology, vol. 22, no. 1, pp. 3-21, 2015.

[6] G. De Francesco and R. Angelini, "Creative autotegulation: towards an interactive urban landscape," in Proceedings of the 2014 International Conference on Intelligent Environments, pp. 388-391, Shanghai, China, June 2014.

[7] X. Zhang, Z. Li, D. Li, and Y. He, "Marine environment distinctions and change law based on eCongnition remote sensing technology," Journal of Coastal Research, vol. 94, no. sp1, pp. 107-111, 2019a.

[8] F. Caprotti and R. Cowley, "Varieties of smart urbanism in the UK: discursive logics, the state and local urban context," Transactions of the Institute of British Geographers, vol. 44, no. 3, pp. 587-601, 2019.

[9] Z. Li, Y. N. Cheng, S. Song, and Y. K. He, "Research on the space cognitive model of new Chinese style landscape based on the operator optimization genetic algorithm," Fresenius Environmental Bulletin, vol. 28, no. 6, pp. 4483-4491, 2019.

[10] M. Carmona, "London's local high streets: the problems, potential and complexities of mixed street corridors," Progress in Planning, vol. 100, pp. 1-84, 2015.

[11] C. Perera, A. Zaslavsky, P. Christen, and D. Georgakopoulos, "Sensing as a service model for smart cities supported by Internet of Things," Transactions on Emerging Telecommunications Technologies, vol. 25, no. 1, pp. 81-93, 2014.

[12] O. A. Hosny, E. M. Dorra, K. A. Tarabieh et al., "Development of an automated optimizer for sustainable urban landscape design," Automation in Construction, vol. 94, pp. 93-103, 2018.

[13] Y. Bae and S. Lee, "A case study on the environmental color of urban regeneration in modern streets - focused on the color of historic and surrounding buildings on marunouchi street and Bashamichi street," Journal of Korea Society of Color Studies, vol. 33, no. 2, pp. 38-48, 2019.

[14] T. Alizadeh, "An investigation of IBM's Smarter Cites Challenge: what do participating cities want?" Cities, vol. 63, pp. 70-80, 2017.

[15] A. H. Sodhro, S. Pirbhulal, Z. Luo, and V. H. C. de Albuquerque, "Towards an optimal resource management for IoT based green and sustainable smart cities," Journal of Cleaner Production, vol. 220, pp. 1167-1179, 2019.

[16] Z. Li, Y. N. Cheng, and Y. Y. Yuan, "Research on the application of virtual reality technology in landscape design teaching," Educational Sciences: Theory and Practice, vol. 16, no. 5, pp. 1400-1410, 2018a.

[17] Y. Shen, "Create synergies and inspire collaborations around the development of intelligent infrastructure for humancentered communities," Journal of the Association for Information Science and Technology, vol. 70, no. 6, pp. 596-606, 2019.

[18] P. Mohandas, J. S. A. Dhanaraj, and X.-Z. Gao, "Artificial neural network based smart and energy efficient street lighting system: a case study for residential area in hosur," Sustainable Cities and Society, vol. 48, Article ID 101499, 2019.

[19] Z. Shen and M. Kawakami, "An online visualization tool for Internet-based local townscape design," Computers, Environment and Urban Systems, vol. 34, no. 2, pp. 104-116, 2010.

[20] S. Rinaldi, F. Bittenbinder, C. Liu, P. Bellagente, L. C. Tagliabue, and A. L. C. Ciribini, "Bi-directional interactions between users and cognitive buildings by means of smartphone app," in Proceedings of the 2016 IEEE International Smart Cities Conference (ISC2), pp. 490-495, Trento, Italy, September 2016.

[21] L. Cheng, S. Chen, S. Chu et al., "LiDAR-based three-dimensional street landscape indices for urban habitability," Earth Science India, vol. 10, no. 4, pp. 457-470, 2017.

[22] S. Wolfert, L. Ge, C. Verdouw, and M.-J. Bogaardt, "Big data in smart farming-a review," Agricultural Systems, vol. 153, pp. 69-80, 2017.

[23] M. S. Munir, I. S. Bajwa, M. A. Naeem, and B. Ramzan, "Design and implementation of an IoT system for smart energy consumption and smart irrigation in tunnel farming," Energies, vol. 11, no. 12, p. 3427, 2018.

[24] F. Canales-Ide, S. Zubelzu, and L. Rodríguez-Sinobas, "Irrigation systems in smart cities coping with water scarcity: the case of Valdebebas, Madrid (Spain)," Journal of Environmental Management, vol. 247, pp. 187-195, 2019.

[25] J. M. Blonquist, S. B. Jones, and D. A. Robinson, "Precise irrigation scheduling for turfgrass using a subsurface electromagnetic soil moisture sensor," Agricultural Water Management, vol. 84, no. 1-2, pp. 153-165, 2006.

[26] L. Heeb, "Climate-smart pest management: building resilience of farms and landscapes to changing pest threats," Journal of Pest Science, vol. 92, no. 3, pp. 951-969, 2019.

[27] Z. Li, X. Han, X. Lin, and X. Lu, "Quantitative analysis of landscape efficacy based on structural equation modelling: empirical evidence from new Chinese style commercial streets," Alexandria Engineering Journal, vol. 60, no. 1, pp. 261-271, 2021. 
[28] A. Costin and C. Eastman, "Need for interoperability to enable seamless information exchanges in smart and sustainable urban systems," Journal of Computing in Civil Engineering, vol. 33, no. 3, 2019.

[29] Z. Li, Y. Cheng, and R. Xiao, "Electroencephalogram experiment based analysis of aesthetic fatigue on Chinese traditional garden," NeuroQuantology, vol. 16, no. 5, pp. 356-362, 2018b.

[30] C. Balakrishna, "Enabling technologies for smart city services and applications," in Proceedings of the 2012 Sixth International Conference on Next Generation Mobile Applications, Services and Technologies, pp. 223-227, Paris, France, September 2012.

[31] K. Mandula, R. Parupalli, C. AS. Murty, E. Magesh, and R. Lunagariya, "Mobile based home automation using internet of things (IoT)," in Proceedings of the 2015 International Conference on Control, Instrumentation, Communication and Computational Technologies (ICCICCT), pp. 340-343, Nagercoil, India, December 2015.

[32] F. Zhang, L. Wu, D. Zhu, and Y. Liu, "Social sensing from street-level imagery: a case study in learning spatio-temporal urban mobility patterns," ISPRS Journal of Photogrammetry and Remote Sensing, vol. 153, pp. 48-58, $2019 \mathrm{~b}$.

[33] L. Caneparo, "Shared virtual reality for design and management: the Porta Susa project," Automation in Construction, vol. 10, no. 2, pp. 217-228, 2001.

[34] J. Ching, D. Aliaga, G. Mills et al., "Pathway using WUDAPT's Digital Synthetic City tool towards generating urban canopy parameters for multi-scale urban atmospheric modeling," Urban Climate, vol. 28, 2019.

[35] C. R. Bruns and B. C. Chamberlain, "The influence of landmarks and urban form on cognitive maps using virtual reality," Landscape and Urban Planning, vol. 189, pp. 296-306, 2019.

[36] V. Gazis, M. Strohbach, N. Akiva, and M. Walther, “A unified view on data path aspects for sensing applications at a smart city scale," in Proceedings of the 2013 IEEE 27th International Conference on Advanced Information Networking and Applications Workshops (WAINA), pp. 1283-1288, Barcelona, Spain, March 2013.

[37] H. Khachatryan, D. H. Suh, W. Xu, P. Useche, and M. D. Dukes, "Towards sustainable water management: preferences and willingness to pay for smart landscape irrigation technologies," Land Use Policy, vol. 85, pp. 33-41, 2019.

[38] N. Tcholtchev, P. Lammel, R. Scholz, Y. Rebahi, W. Konitzer, and I. Schieferdecker, "Enabling the structuring, enhancement and creation of urban ICT through the extension of a standardized smart city reference model," in Proceedings of the 2018 IEEE/ACM International Conference on Utility and Cloud Computing Companion (UCC Companion), pp. 121127, Zurich, Switzerland, December 2018.

[39] H. P. McKenna, "Innovating metrics for smarter, responsive cities," Data, vol. 4, no. 1, 2019. 